\title{
Numerical Analysis of Effect of Pin Tip Radius on Residual Stress Distribution in Ultrasonic Impact Treatment*1
}

\author{
Takahiro Ohta ${ }^{* 2}$ \\ School of Engineering, Tokai University, Hiratsuka 259-1292, Japan
}

\begin{abstract}
Ultrasonic impact treatment (UIT) is currently used in several manufacturing processes. UIT is a process in which ultrasonic vibration is used to impact pins onto a metal surface. To clarify the mechanisms of deep compressive residual stress in UIT, the effects of the pin tip radius on residual stress distributions were analyzed by the dynamic explicit finite element method. The sonotrode vibration amplitude and frequency were $25 \mu \mathrm{m}$ and $20 \mathrm{kHz}$, respectively. The pin velocity accelerated by the sonotrode was approximately $4.6 \mathrm{~m} \cdot \mathrm{s}^{-1}$ at the first impact. The depth of the residual compressive stress remained nearly constant after the first impact for pins of various tip radii (1.5, 3, 8 and $12 \mathrm{~mm})$. During the first $10 \mathrm{~ms}$, eleven impacts occurred between the $8 \mathrm{~mm}$ tip radius pin and the metal surface. The pin velocities were highly dependent on the sonotrode velocity in the collision range from 4 to $16 \mathrm{~m} \cdot \mathrm{s}^{-1}$. The depth of residual compressive stress increased with increasing impact number. After $10 \mathrm{~ms}$, the depth of residual compressive stress was approximately $2.5 \mathrm{~mm}$ when using an 8 mm tip radius pin, and it increased with increasing tip radius. [doi:10.2320/matertrans.P-M2018805]
\end{abstract}

(Received September 8, 2017; Accepted December 25, 2017; Published March 25, 2018)

Keywords: finishing, sheet metal forming, shot peening, residual stress, elastic-plastic FEM

\section{Introduction}

Shot peening is a technique that applies compressive residual stress on a metallic surface by impacting it with round steel shots. Because it can easily improve fatigue strength, it is widely adopted by the automotive and airplane industries. In addition to imparting compressive residual stress to metallic surfaces, shot peening is employed in forming. The outer skins of airplane wings are difficult to form by stamping owing to their large size and complex shape; instead, peen forming is used. ${ }^{1-3)}$ Peen forming is a technique to form metal sheets by impacting a shot of a few millimeters in diameter on its external surface to stretch it. Wings with outer skins unified with stringers (beams) are becoming more common; ${ }^{2)}$ however, the forming thereof requires the application of a large strain on the surface.

In recent years, ultrasonic shot peening (USP) and ultrasonic impact treatment (UIT), which uses a pin as a projectile, have been developed. Both are widely used to improve the fatigue strength of welded parts. ${ }^{4-6)}$ Compared to standard peening, these techniques enable compressive stress to be applied to deeper areas below the surface. Desfontaine et al. demonstrated that when UIT is applied to welded carbon steel using pins three and four millimeters in diameter, it is possible to introduce compressive residual stress to a depth of approximately two millimeters below the surface. ${ }^{4)}$ While analyzing the application of UIT on the forming process of outer skins of airplane wings, Kuroi et al. demonstrated that when UIT is applied to a high-strength aluminum alloy, it is possible to introduce compressive residual stress to approximately two millimeters below the surface, and its forming capacity is higher than that of standard peen forming. ${ }^{3)}$ However, in contrast to peening with a sphere, peening with a pin has no unique definition of the relationship between the curvature radius of the contact

\footnotetext{
${ }^{* 1}$ This Paper was Originally Published in Japanese in J. JSTP 58 (2017) 35-40.

${ }^{* 2}$ Corresponding author, E-mail: takahiro_ohta@tsc.u-tokai.ac.jp
}

surface and the mass; this increases the number of parameters. Conventional studies of shot peening assume a sphere as the projectile, and there is no analysis that separates the curvature radius of the contact surface from the mass. In addition, the projection velocity in ultrasonic shot peening varies up to a maximum of at $18 \mathrm{~m} \cdot \mathrm{s}^{-1}$, and many experimental and analytical studies have reported values of $6 \mathrm{~m} \cdot \mathrm{s}^{-1}$ or less. ${ }^{7,8)}$ This velocity is lower than that of standard shot peening, which reaches tens of $\mathrm{m} \cdot \mathrm{s}^{-1}$, and the mechanism that allows UIT to impart deeper compressive residual stress than standard shot peening remains unclear.

Therefore, this study aims to identify the effect of pin tip radius on the movement of ultrasonic sonotrodes and pins, as well as on the residual stress on a UIT workpiece using axisymmetric dynamic explicit finite element analysis.

\section{Analysis Method}

UIT is a method in which ultrasonic vibration generated by piezoelectric elements is resonated, amplified, and transmitted to the shot material (pin) through a sonotrode. The workpiece is peened when the pin accelerated by the ultrasonic vibration collides with it. The frequency $f$ is determined by the specific frequency of the device, and normally ranges from 20 to $30 \mathrm{kHz}$. In addition, the peening strength is adjusted by amplitude $A$, and normally varies between 20 and $60 \mu \mathrm{m}$. Supposing the vibration has the shape of a sine wave, the displacement $z_{(t)}$ at time $t$ is indicated by eq. (1):

$$
z_{(t)}=A \cdot \sin (2 \pi f t)
$$

Moreover, its velocity $v_{(t)}$ at this moment is expressed by eq. (2):

$$
v_{(t)}=2 \pi A f \cdot \cos (2 \pi f t)
$$

In the analysis of this study, it is assumed that the sonotrode has a frequency $f$ of $20 \mathrm{kHz}$ and vibrates with a sine wave of amplitude $A$ of $25 \mu \mathrm{m}$. The maximum velocity calculated with eq. (2) is $3.14 \mathrm{~m} \cdot \mathrm{s}^{-1}$, which is lower than the 


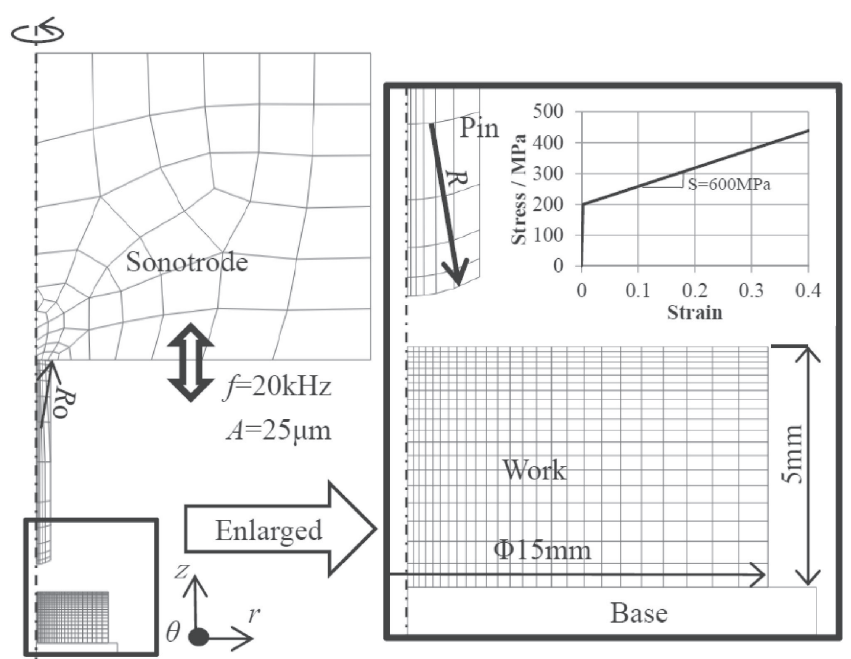

Fig. 1 Analysis model.

impact velocity of standard shot peening of tens of $\mathrm{m} \cdot \mathrm{s}^{-1}$. The velocity of the pin is greatly influenced not only by the frequency and amplitude of the sonotrode, but also by the shape and material of the pin tip that contacts the sonotrode. However, in this study, it was set as constant.

The analysis model is shown in Fig. 1. The sonotrode used is an elastic body (Young's modulus $E_{1}: 210 \mathrm{GPa}$; Poisson's ratio $v_{1}: 0.33$; density $\rho: 7.8 \times 10^{3} \mathrm{~kg} / \mathrm{m}^{3}$ ) with a diameter and height of 70 and $30 \mathrm{~mm}$, respectively. The projectile (pin) has a diameter and length of 3 and $20 \mathrm{~mm}$, respectively, and the tip curvature radii $R$ that contact the workpiece are 1.5, 3, 8 and $12 \mathrm{~mm}$. Moreover, the curvature radius $R_{\mathrm{o}}$ that contacts the sonotrode was kept constant at $8 \mathrm{~mm}$. The pin is an elastic body (Young's modulus $E_{2}: 210 \mathrm{GPa}$; Poisson's ratio $\nu_{2}$ : 0.33; density $\rho: 7.8 \times 10^{3} \mathrm{~kg} / \mathrm{m}^{3}$ ). Owing to the variation in tip curvature radius $R$ that contacts the workpiece, the volume of the pins has a variance of $2.2 \%$, from a minimum of approximately $137 \mathrm{~mm}^{3}$ to a maximum of $140 \mathrm{~mm}^{3}$. In addition, the volume of the sonotrode is $1.15 \times 10^{5} \mathrm{~mm}^{3}$, which is 822 times larger than that of the pin. The aluminum alloy workpiece is an approximated bilinear elastoplastic body (Young's modulus E: $70 \mathrm{GPa}$; Poisson's ratio: 0.3; density $\rho: 2.7 \times 10^{3} \mathrm{~kg} / \mathrm{m}^{3}$; yield stress: $200 \mathrm{MPa}$; plastic tangent coefficient $S: 600 \mathrm{MPa}$. Refer to Fig. 1). The distance from the center of the sonotrode's amplitude to the workpiece was set at $22.7 \mathrm{~mm}$. The strain rate dependence of deformation resistance at room temperature is small, and thus was not considered in this study. The workpiece thickness and outer diameter were set at 5 and $15 \mathrm{~mm}$, respectively. The mesh was divided into 20 parts in the thickness direction at an increasing rate of 1.09 times, from a minimum of $9.95 \times 10^{-2} \mathrm{~mm}$ to a maximum of $0.498 \mathrm{~mm}$. In the radial direction, it was divided into 25 parts, at an increasing rate of 1.07 times, from a minimum of $0.120 \mathrm{~mm}$ to a maximum of $0.598 \mathrm{~mm}$. Because the temperature increase of a single impact of shot peening was estimated by Rouquette et al. to be less than $100^{\circ} \mathrm{C},{ }^{9}$ ) it was not considered in this study; the influence of gravity and air resistance were ignored. The friction between the pin and the workpiece is defined as Coulomb friction, and the friction coefficient $\mu$ was set as 0.3 . For the contact model between surfaces, the pin side was set as the master and the workpiece side as the slave. Manoucherifar et al. demonstrated that a friction coefficient $\mu$ of 0.1 to 0.8 between the shot and the workpiece does not influence the residual stress distribution. ${ }^{10)}$ To analyze the details of multiple impacts of a single pin in a short period of time (0 to $10 \mathrm{~ms}$ ), I carried out an axisymmetric analysis using the dynamic explicit method of ABAQUS Explicit (Ver. 6.8). Although the residual stress vibrated at an amplitude of approximately $20 \mathrm{MPa}$, because the analysis was conducted using a dynamic explicit method, the central value of amplitude was used as the residual stress at that instant.

\section{Analysis Result and Discussion}

\subsection{Effect of tip curvature radius on a single impact}

To examine the effect of the tip curvature radius $R$, I analyzed the strain and residual stress distributions inside the workpiece after a single impact. The impact velocity $v_{\mathrm{b}}$ of the pin on the workpiece was $4.62 \mathrm{~m} \cdot \mathrm{s}^{-1}$ for $R=1.5 \mathrm{~mm}$, $4.55 \mathrm{~m} \cdot \mathrm{s}^{-1}$ for $R=3 \mathrm{~mm}, 4.56 \mathrm{~m} \cdot \mathrm{s}^{-1}$ for $R=8 \mathrm{~mm}$, and $4.53 \mathrm{~m} \cdot \mathrm{s}^{-1}$ for $R=12 \mathrm{~mm}$; this is a velocity variation of $2.0 \%$. This velocity is higher than that of the sonotrode $\left(3.14 \mathrm{~m} \cdot \mathrm{s}^{-1}\right)$, calculated using eq. (2). Figure 2 shows the time variation of the displacement of both the sonotrode and the top and center of the pin, for $R=8 \mathrm{~mm}$. At the start of the analysis, the top of the pin is at the center of the amplitude of the sonotrode, and contact occurs when the displacement of the sonotrode decreases to zero. Then, the top of the pin is subject to an elastic deformation as it starts to move downwards. The difference in displacement between the center and the top of the pin in the Fig. 2 represents the elastic deformation of the top of the pin.

Figure 3 shows the variation in velocity. The pin detaches from the sonotrode when the velocity of the sonotrode is approximately $-1 \mathrm{~m} \cdot \mathrm{s}^{-1}$; however, when a contact load is added, it accelerates faster than the sonotrode. As shown in Fig. 3, the pin vibrates after the impact; however, I use the average impact velocity value. According to Hertz's contact stress equation, the relationship between the displacement of the pin tip $\delta$ and contact load $P$ can be represented as follows: ${ }^{11)}$

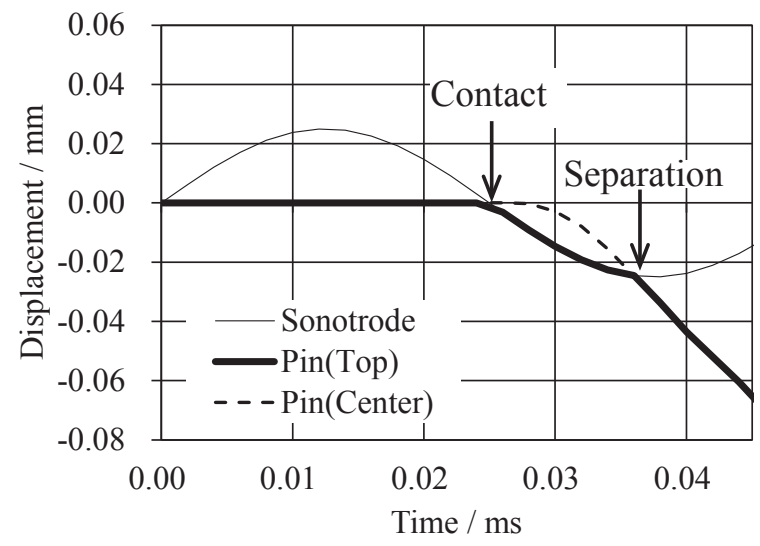

Fig. 2 Histories of pin and sonotrode displacement in $\mathrm{z}$ direction around 1 st collision. 


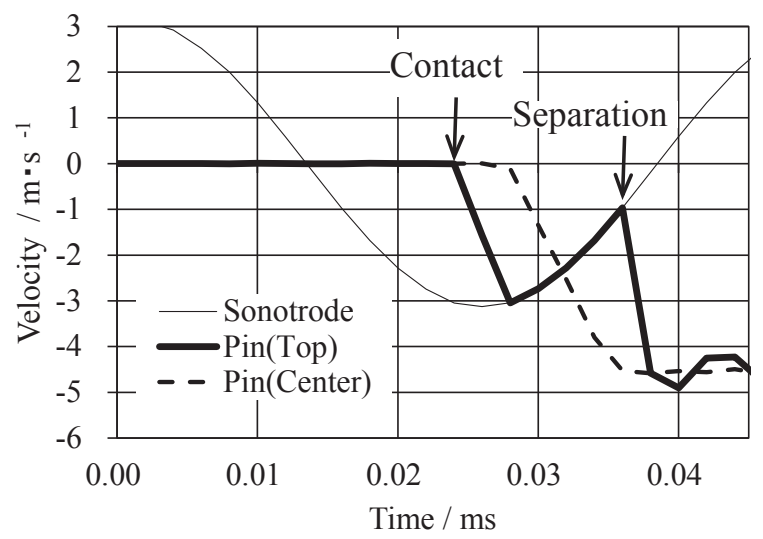

Fig. 3 Histories of pin and sonotrode velocity in $\mathrm{z}$ direction around $1 \mathrm{st}$ collision.
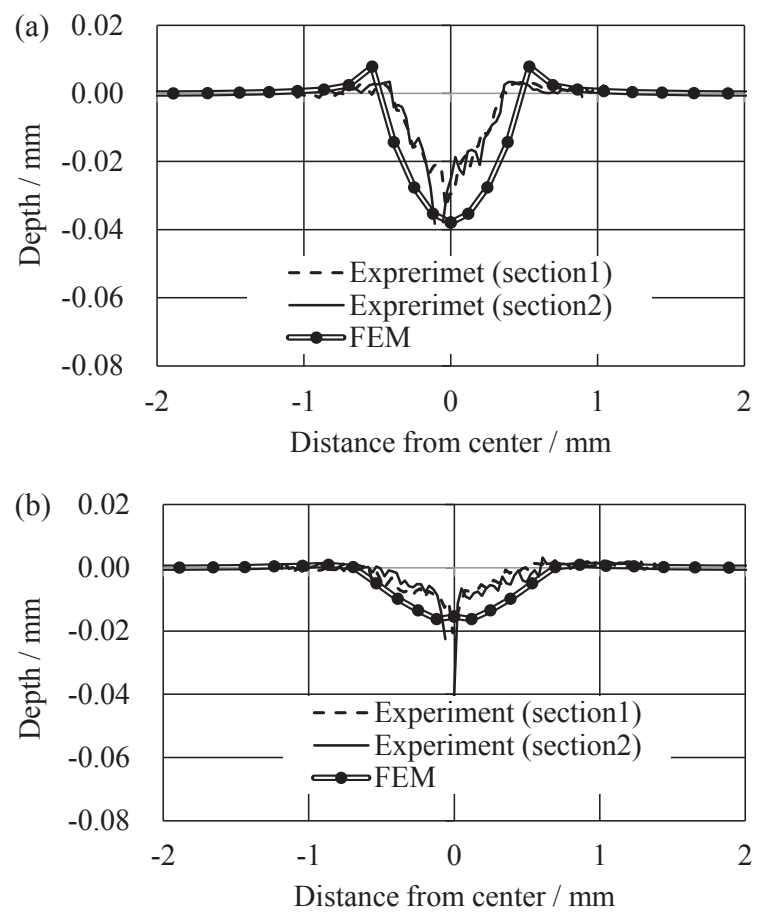

Fig. 4 Effect of tip radius on surface profiles after 1st impact. (a) $R=3 \mathrm{~mm}$ (b) $R=12 \mathrm{~mm}$.

$$
\delta^{3}=\frac{9}{16} \frac{1}{R_{o}}\left(\frac{1-v_{1}^{2}}{E_{1}}+\frac{1-v_{2}^{2}}{E_{2}}\right)^{2} P^{2}
$$

Here, $E_{1}$ and $E_{2}$ are the Young's moduli and $v_{1}$ and $v_{2}$ are the Poisson's ratios of the sonotrode and pin, respectively; $R_{\mathrm{o}}$ is the curvature radius of the top of the pin that contacts the sonotrode. The maximum displacement $\delta$ is $1.18 \times 10^{-2} \mathrm{~mm}$, which results in a contact load $P$ of $558 \mathrm{~N}$ when substituted into eq. (3). Supposing this contact load accelerates the pin, the acceleration is $5.11 \times 10^{5} \mathrm{~m} \cdot \mathrm{s}^{-2}$. In Fig. 3, the pin contacts the sonotrode for $1.2 \times 10^{-5} \mathrm{~s}$; thus, the velocity is increased to approximately $6.1 \mathrm{~m} \cdot \mathrm{s}^{-1}$. In reality, the contact load changes with time; thus, this calculation is not precise, but it is noticeable that the pin is accelerated by the contact load.

Figure 4 shows the analysis result of the displacement (indentation) on the workpiece surface after a single impact with $R=3$ and $12 \mathrm{~mm}$. For $R=3 \mathrm{~mm}$, the indentation is

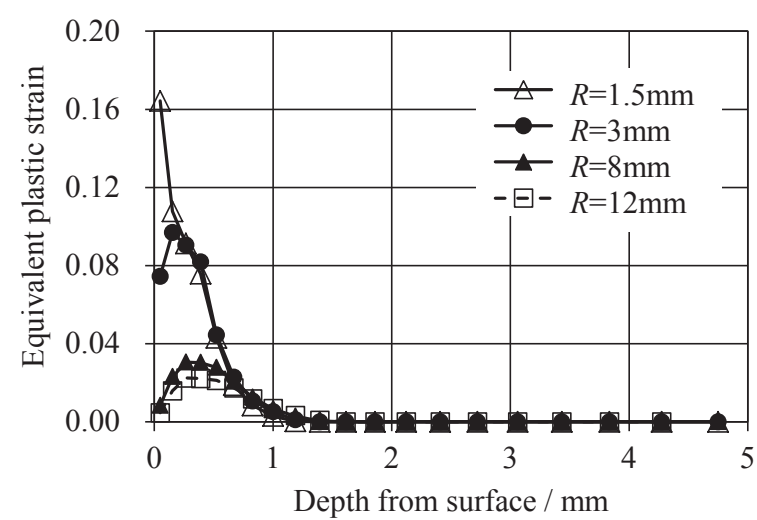

Fig. 5 Effect of tip radius on equivalent plastic strain distribution along center line after 1 st impact. (a)

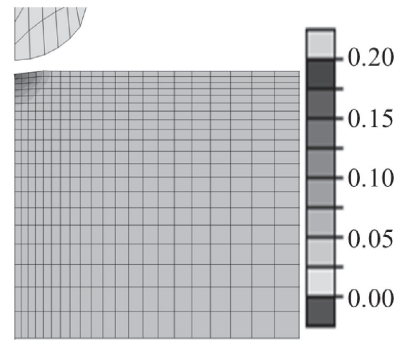

(b)

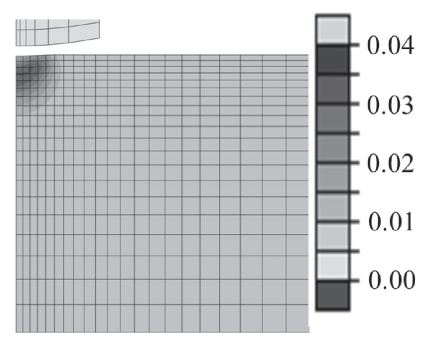

Fig. 6 Distribution of equivalent plastic strain after 1st impact. (a) $R=1.5 \mathrm{~mm}$ (b) $R=8 \mathrm{~mm}$.

deep and is surrounded by a bulge deformation. In contrast, for $R=12 \mathrm{~mm}$, the indentation is shallow with barely any bulge deformation. For comparison, the experimental result is shown in Fig. 4. The material of the workpiece used in the experiment is aluminum alloy A5052-H112 (tensile strength: $246 \mathrm{MPa}$ ), and a pre-hardened steel (Daido's special steel NAK55) of HRC 37 to 43 was used for the pin. The pin was dropped from a height of one meter at a free fall speed of $4.42 \mathrm{~m} \cdot \mathrm{s}^{-1}$. The indentation shape was measured with two orthogonal cross-sections. The indentation of the experimental result is somewhat smaller than that of the analysis result; however, it demonstrates that the analysis can simulate the effect of the tip curvature radius $R$.

The equivalent plastic strain distribution inside the workpiece upon single impact, and the contour chart of equivalent plastic strain for $R=1.5$ and $8 \mathrm{~mm}$ are shown in Fig. 5 and Fig. 6, respectively. The tip curvature radius $R$ had little effect on the depth to which the equivalent plastic strain was induced; in all cases, it was approximately $1.2 \mathrm{~mm}$. In contrast, the equivalent plastic strain close to the surface was largely influenced by $R$; the smaller $R$, the larger the strain. In addition, for $R=3,8$, and $12 \mathrm{~mm}$, the strain on the surface was small, and their peak distribution lay inside the workpiece. As Fig. 6 shows, in the case of $R=1.5 \mathrm{~mm}$, the strain is concentrated on a single element of the surface owing to the small contact area. As a result, the distribution close to the surface is different. Normally, when the shot material is spherical, the larger its radius, the deeper the equivalent plastic strain. For pins, because the mass is almost equivalent, the kinetic energy is practically constant, causing little difference in the depth of the equivalent plastic strain 


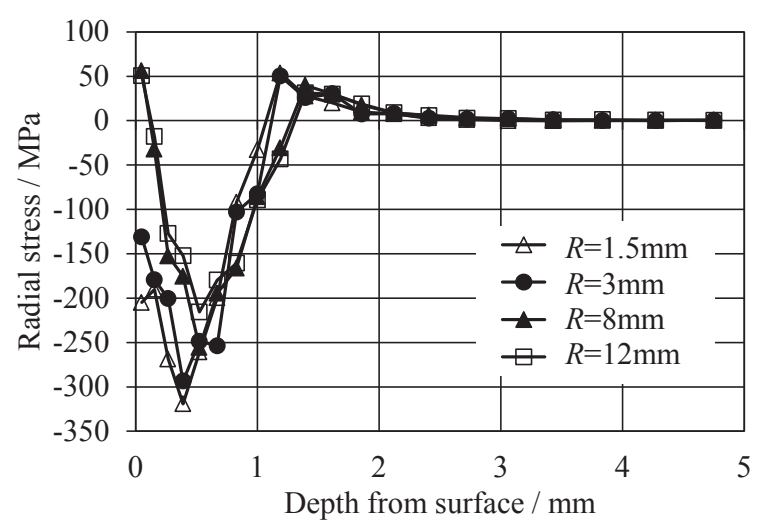

Fig. 7 Effect of tip radius on residual radial stress distribution along center line after 1st impact. (a)

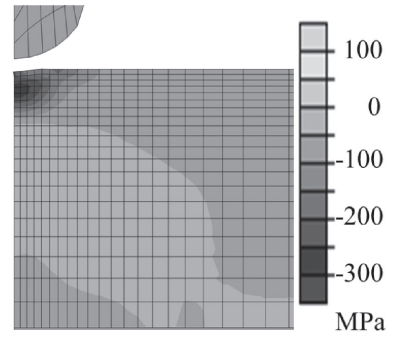

(b)

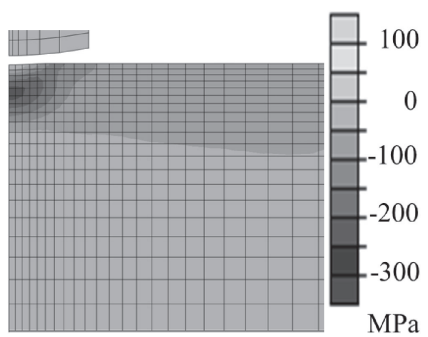

Fig. 8 Distribution of residual radial stress after 1 st impact. (a) $R=1.5 \mathrm{~mm}$ (b) $R=8 \mathrm{~mm}$.

distribution. This result suggests that kinetic energy exerts a large influence on the depth of equivalent plastic strain.

The radial residual stress distribution inside the workpiece after a single impact, and the contour chart of radial stress for $R=1.5$ and $8 \mathrm{~mm}$ are shown in Fig. 7 and Fig. 8, respectively. The residual stress on the single impact surface for $R=1.5$ and $3.0 \mathrm{~mm}$ acts as compressive stress; however, at $R=8$ and $12 \mathrm{~mm}$, it becomes tensile stress. The same trend has been reported for shot diameters: the surface undergoes compressive stress if the shot diameter is small, and tensile stress if it is large. ${ }^{12)}$ As shown in Fig. 8, the compressive residual stress is present over a wide area in the radial direction, both for $R=1.5$ and $8 \mathrm{~mm}$, but the tensile residual stress close to the surface only remains in the central part of the indentation for $R=8 \mathrm{~mm}$. The depth of compressive residual stress is almost equivalent for $R=1.5$ to $12 \mathrm{~mm}$, which suggests that the depth of compressive residual stress is largely influenced by the kinetic energy, in a similar way as the distribution of equivalent plastic strain.

\subsection{Effect of multiple impacts}

In UIT, the pin executes the peening through a back-andforth motion in the space between the sonotrode and the workpiece. The head is reported to move at a speed of 5 or $8 \mathrm{~mm} \cdot \mathrm{s}^{-1}{ }^{4,6)}$ In the case of UIT, because the pin is held by a guide, it executes the back-and-forth motion in the same position. Over a period of $10 \mathrm{~ms}$, it moves through a maximum distance of 0.05 to $0.08 \mathrm{~mm}$. It is likely that, when the outer diameter of the pin is $3 \mathrm{~mm}$, the movement amount relative to the outer diameter is small; therefore, multiple impacts occur in practically the same position.

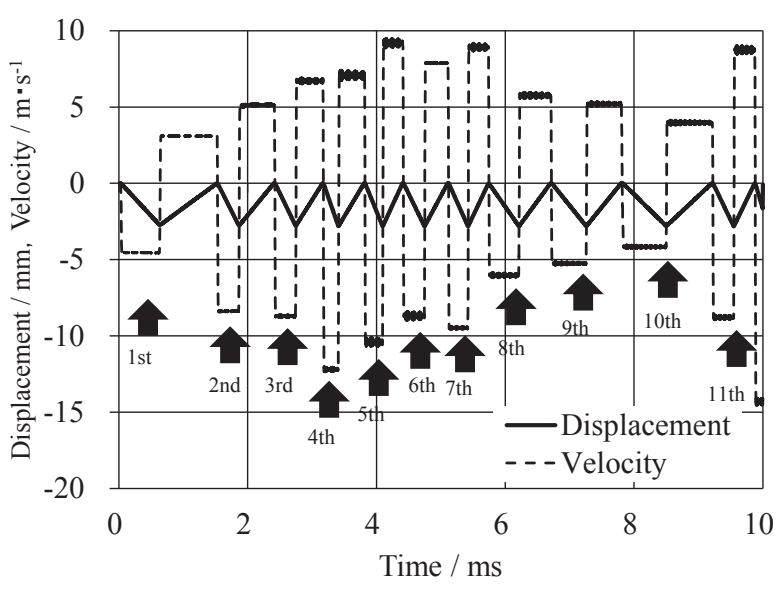

Fig. 9 Histories of pin displacement and velocity $(R=8 \mathrm{~mm})$.

For this reason, this analysis focuses on the behavior of the pin during the period of 0 to $10 \mathrm{~ms}$. Figure 9 shows the movement of the pin for $R=8 \mathrm{~mm}$. In this case, the pin impacted the workpiece 11 times in $10 \mathrm{~ms}$, in a velocity range of 4.20 to $12.2 \mathrm{~m} \cdot \mathrm{s}^{-1}$. The impact velocity was the highest in the fourth impact. This velocity range is almost the same as that of the analysis result of the USP conducted by Rousseau et al. $^{7 \text { ) }}$

The impact velocity of the pin probably depends on the velocity of the sonotrode when it collides with the pin, and the rebound velocity of the pin. Hence, the velocity changed on the fourth (accelerated) and eighth (decelerated) collisions of the sonotrode and pin, as shown in Fig. 10. It can be seen that, during the fourth impact, the sonotrode collided with the pin while accelerating downwards (negative side), accelerating the pin. Meanwhile, during the eighth impact, the sonotrode collided with the pin while accelerating upwards (positive side), thereby decelerating the pin. The contact loads of the fourth and eighth impacts, calculated using eq. (3), were 912 and $382 \mathrm{~N}$, respectively, which correspond to the velocity change in the pin. These findings indicate that, because the movement of the pin and the vibration of the sonotrode are not synchronized, the downward velocity of the pin changes according to the velocity of the sonotrode during collision with the pin.

Figure 11 shows the variation in equivalent plastic strain distribution inside the workpiece for $R=8 \mathrm{~mm}$. The peak equivalent plastic strain increases with increasing number of impacts, as does the depth of induced strain. After the fourth impact, it remains fairly constant. In addition, the plastic strain on the surface increases with the number of impacts. As shown in Fig. 9, as the velocity of impact increases from $4.56 \mathrm{~m} \cdot \mathrm{s}^{-1}$ in the first collision to $8.38 \mathrm{~m} \cdot \mathrm{s}^{-1}$ in the second; the difference in plastic strain between the two impacts increased. However, since the difference in velocity with the third impact $\left(8.75 \mathrm{~m} \cdot \mathrm{s}^{-1}\right)$ is small, the variation in plastic strain is also small. During the fourth impact, $v_{\mathrm{b}}$ reaches its highest velocity at $14.6 \mathrm{~m} \cdot \mathrm{s}^{-1}$; thus, the variation in plastic strain is large, but the impact velocity decreases thereafter, decreasing the variation. From the velocity change shown in Fig. 9, it is possible to analyze the ratio between the velocity of impact of the workpiece and pin, $v_{\mathrm{b}}$, and the rebound velocity, $v_{\mathrm{a}}$. The $v_{\mathrm{a}} / v_{\mathrm{b}}$ ratio is $68 \%$ in the first impact, $61 \%$ 

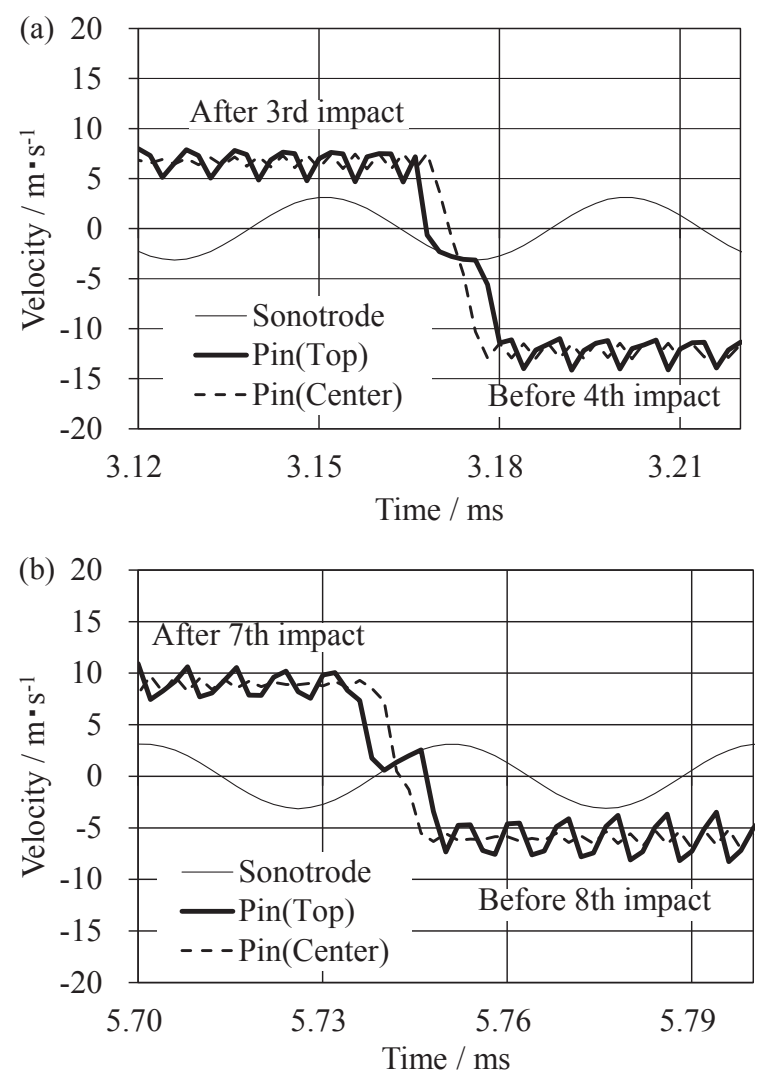

Fig. 10 Histories of pin and sonotrode velocity in $\mathrm{z}$ direction around 4th and 8 th collision $(R=8 \mathrm{~mm}$ ). (a) 4 th collision between pin and sonotrode (b) 8th collision between pin and sonotrode.

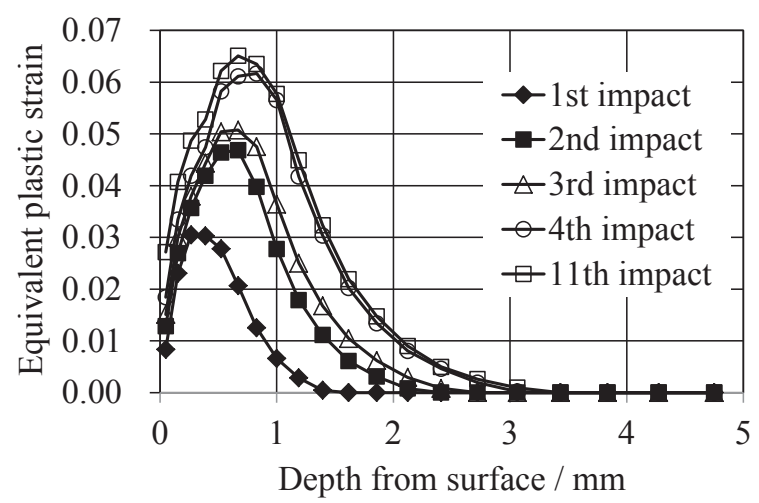

Fig. 11 Effect of impact number on equivalent plastic strain distribution along center line $(R=8 \mathrm{~mm})$.

in the second, $77 \%$ in the third, $59 \%$ in the fourth, and 90 to $100 \%$ from the fifth impact onward. The trend in change in velocity of the pin (kinetic energy) matches that of the plastic strain.

Figure 12 shows the variation in radial residual stress inside the workpiece for $R=8 \mathrm{~mm}$. It shows a trend similar to the variation in plastic strain; as the number of impacts increases, the peak compressive residual stress increases, and the area of compressive stress becomes deeper. Moreover, the initial residual stress of the surface is tensile stress, but it becomes compressive stress after the 11th impact.

During the period of 0 to $10 \mathrm{~ms}$, there were seven impacts $\left(v_{\mathrm{b}}=2.80\right.$ to $\left.10.5 \mathrm{~m} \cdot \mathrm{s}^{-1}\right)$ with $R=1.5 \mathrm{~mm}$, eight $\left(v_{\mathrm{b}}=4.54\right.$ to $\left.11.5 \mathrm{~m} \cdot \mathrm{s}^{-1}\right)$ with $R=3 \mathrm{~mm}$, and $12 \quad\left(v_{\mathrm{b}}=3.50\right.$ to

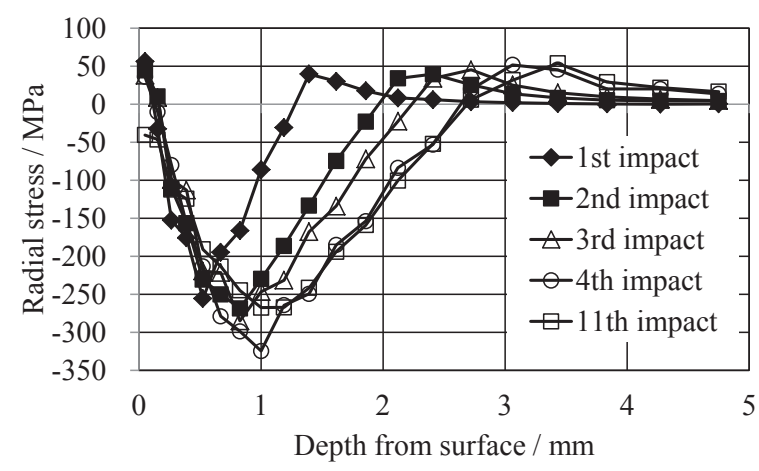

Fig. 12 Effect of impact number on residual radial stress distribution along center line $(R=8 \mathrm{~mm})$

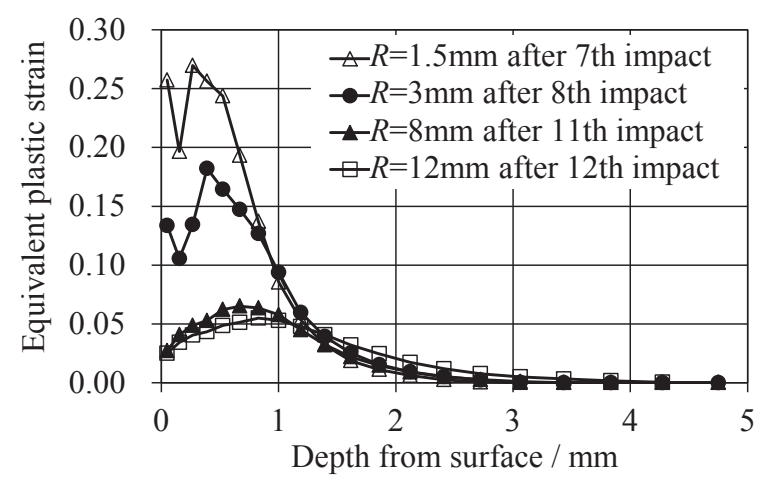

Fig. 13 Effect of tip radius on equivalent plastic strain distribution along center line after $10 \mathrm{~ms}$. (a)

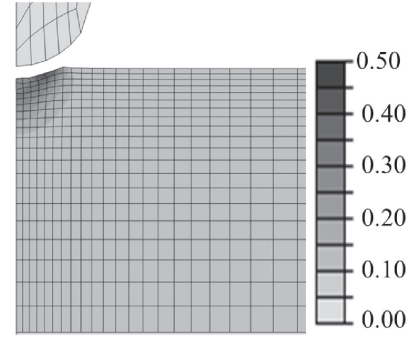

(b)

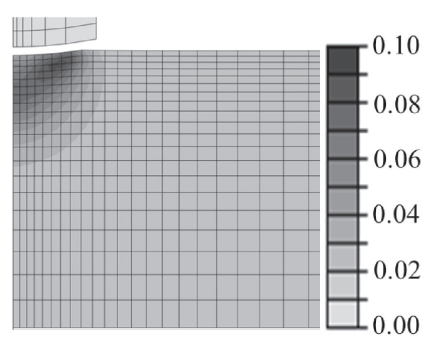

Fig. 14 Distribution of equivalent plastic strain after $10 \mathrm{~ms}$. (a) $R=$ $1.5 \mathrm{~mm}$ (b) $R=8 \mathrm{~mm}$.

$16.1 \mathrm{~m} \cdot \mathrm{s}^{-1}$ ) with $R=12 \mathrm{~mm}$. As shown in Fig. 5, a smaller $R$ corresponds to a larger plastic strain on the workpiece, which reduces both the rebound velocity of the workpiece after the impact, $v_{\mathrm{a}}$, and the number of impacts. Figure 13 shows the variation in equivalent plastic strain distribution inside the workpiece after $10 \mathrm{~ms}$, and Fig. 14 shows the contour chart of equivalent plastic strain for $R=1.5$ and $8 \mathrm{~mm}$.

In addition, Fig. 15 shows the radial residual stress distribution inside the workpiece after $10 \mathrm{~ms}$, and Fig. 16 shows the contour chart of radial stress for $R=1.5$ and $8 \mathrm{~mm}$. As shown in Fig. 6 , for $R=1.5 \mathrm{~mm}$, the strain is concentrated initially in a single element of the surface; however, the contour charts in Fig. 14 and 16 show that the absolute values for $R=1.5$ and $8 \mathrm{~mm}$ are different, but the distribution of strain and stress follow the same trend. The smaller the $R$, the larger the plastic strain induced, but at a shorter distance 


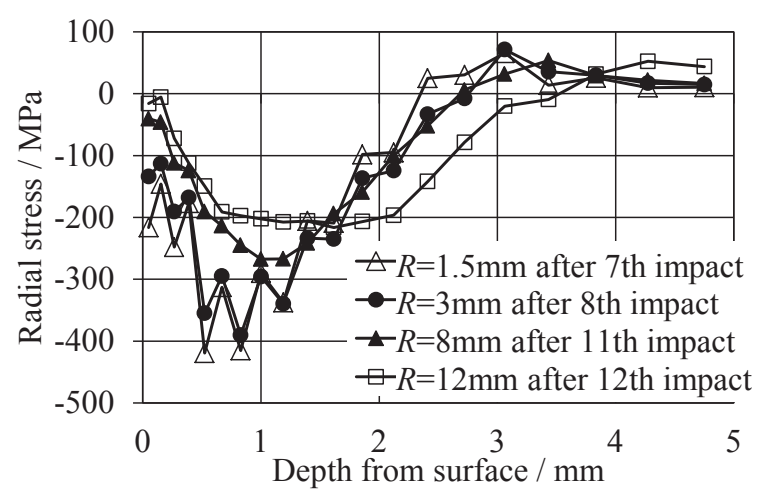

Fig. 15 Effect of tip radius on residual radial distribution along center line after $10 \mathrm{~ms}$.

(a)

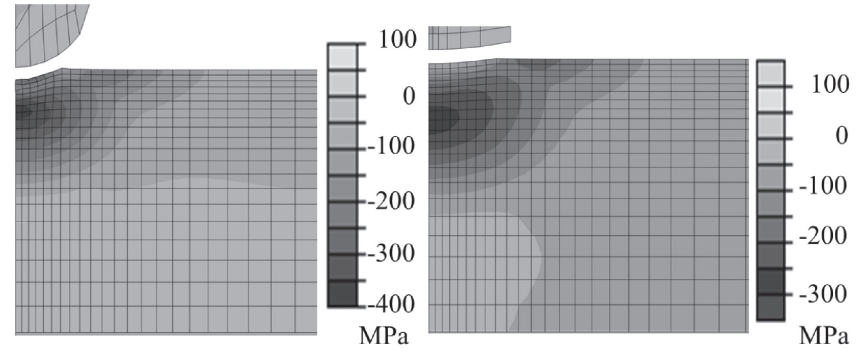

Fig. 16 Distribution of residual radial stress after $10 \mathrm{~ms}$. (a) $R=1.5 \mathrm{~mm}$ (b) $R=8 \mathrm{~mm}$.

from the surface. This same trend applies to radial residual stress: the smaller the $R$, the larger the compressive stress peak, but over a shallower area. Regarding the residual stress on the surface: the smaller the $R$, the larger the compressive stress. The compressive stress on the surface is a minimum at $R=12 \mathrm{~mm}$. However, the effect of the sphere diameter is not as significant as reported in previous studies, ${ }^{12)}$ as the difference in depth of induced residual stress is small.

Because the tensile strain generated on the surface is smaller than that generated in the interior region, the balance between the two generates a tensile elastic strain, and the stress state of the surface converts to tensile stress when the load is relieved. More precisely, if the difference between the internal peak strain and tensile strain on the surface is large, tensile residual stress is generated on the surface, which suggests a correlation between the ratio of strain on the surface to the radial strain on the surface and internal peak strain, and the radial residual stress on the surface. Figure 17 shows the relationship between the ratio of equivalent plastic strain on the surface to the peak equivalent plastic strain after each impact with $R=1.5$ to $12 \mathrm{~mm}$, and the radial residual stress on the center surface. All cases follow a similar trend in which large ratios of equivalent plastic strain on the surface to the maximum value of equivalent plastic strain cause the residual stress on the surface to decrease; moreover, if the ratio exceeds approximately 0.4 , it becomes compressive residual stress. Some of the points for $R=1.5 \mathrm{~mm}$ lie far from the line, but these were probably caused by the strain that concentrated initially on a single element of the surface, as shown in Fig. 6.

As shown in Fig. 16, if the tip curvature radius $R$ is small, the indentation is deep with a surrounding bulging

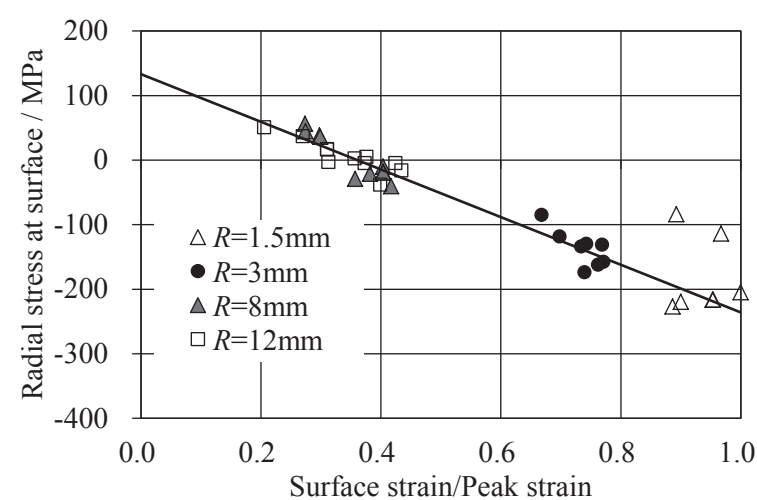

Fig. 17 Relationship between ratio of surface plastic strain to inside peak plastic strain and residual stress at center surface.

deformation. In cases such as shot peen forming, which aims to refine the surface roughness and introduce deeper plastic strain, pins with large $R$ values are suitable. However, for structural refinement through weld toe adjustment and strengthening processes, or to induce residual stress, pins with small $\mathrm{R}$ values are better suited.

\section{Conclusions}

The effect of pin tip radius $R$ on the movement of ultrasonic sonotrodes and pins, as well as on the residual stress of an ultrasonic impact treatment workpiece, was examined using axisymmetric dynamic explicit finite element analysis. The results obtained are as follows:

(1) The velocity of a pin accelerated by a sonotrode vibrating with a sine wave of frequency $20 \mathrm{kHz}$ and amplitude $25 \mu \mathrm{m}$ was approximately 4 to $16 \mathrm{~m} \cdot \mathrm{s}^{-1}$. When the sonotrode collided with the pin while accelerating downwards, the velocity of the pin increased; when it collided with the pin while accelerating upwards, the velocity of the pin decreased.

(2) The depth of compressive residual stress after the first impact was hardly influenced by the tip curvature radius $R$ that contacts the workpiece. There was no difference for $R=1.5$ to $12 \mathrm{~mm}$, and it remained as compressive residual stress up to approximately $1 \mathrm{~mm}$ from the surface. For $R=8$ and $12 \mathrm{~mm}$, the center surface residual stress became tensile stress.

(3) When the pin moved back and forth between the sonotrode and workpiece, 7 to 12 collisions occurred in a period of $10 \mathrm{~ms}$. The larger the $R$, the higher the number of collisions. Multiple collisions increased the depth of compressive residual stress up to 2 to $3 \mathrm{~mm}$. The depth of compressive residual stress tended to increase as $R$ increased.

(4) There was a correlation between the ratio of the equivalent plastic strain on the surface to the maximum value of equivalent plastic strain after the collision, and the radial residual stress on the center surface. For high ratios of equivalent plastic strain on the surface to the maximum value of equivalent plastic strain, the residual stress on the surface decreased; when the ratio exceeded approximately 0.4 , it became compressive residual stress. 


\section{REFERENCES}

1) R. Kopp and F. Wüstefeld: Proceedings of the 4th International Conference on Shot Peening (1990) pp. 561-572.

2) T. Yamada, T. Takahashi, M. Ikeda, S. Sugimoto and T. Ohta: Mitsubishi Heavy Industries, Ltd. Technical Review 39 (2002) 57-61.

3) K. Kuroi, A. Kono, T. Kozaki, M. Handa and S. Sasaki: Proceedings of the 48th Aircraft Symposium (2010) Paper No. 3C9 (in Japanese).

4) D. Desfontaine, P. Montherat, F. Chateau and O. Briere: Proceedings of the 11th International Conference on Shot Peening (2011) pp. 13-18.

5) M. Malaki and H. Ding: Mater. Des. 87 (2015) 1072-1086.

6) T. Nose: J. Japan Welding Soc. 77 (2008) 210-213 (in Japanese).
7) T. Rousseau, T. Hoc, P. Gilles and C. Nouguier-Lehon: J. Mater Process. Technol. 225 (2015) 413-420.

8) P. Thuemmler, H. Polanetzki and V. Schulze: Proceedings of the 10th International Conference on Shot Peening (2008) No. 2008113.

9) S. Rouquette, E. Rouhaud, H. Pron, M. Francois and C. Bissieux: Proceedings of the 9th International Conference on Shot Peening (2005) pp. 113-118

10) A. Manoucherifar and R. Rezvani: Proceedings of the 11th International Conference on Shot Peening (2011) pp. 67-74.

11) I. Nakahara: Zairyou Rikigaku Vol. 2, (Youkendo, Tokyo, 1987) pp. 116-120 (in Japanese).

12) Y. Zang: Proceedings of the 8th International Conference on Shot Peening (2002) pp. 561-572 